\title{
ESPAÇOS VERDES URBANOS: REVENDO PARADIGMAS
}

Romero Gomes Pereira da Silva ${ }^{1}$ Cláudia Lins Lima² Carlos Hiroo Saito ${ }^{3}$

Resumo: Apesar do conceito de áreas verdes urbanas parecer cristalizado na literatura cientifica brasileira, após a promulgação da Lei no 12.651/2012 (conhecida como Novo Código Florestal) o termo passou a ter aplicação diferente, porém pouco difundida. Constatou-se, assim, que o termo "áreas verdes urbanas" não se aplica à maioria dos estudos e análises técnicas-científicas, uma vez que as áreas verdes urbanas teriam de estar localizadas em locais indisponíveis para moradias, conforme explana este artigo. Em seguida, os autores correlacionam áreas verdes urbanas com o termo espaços verdes urbanos, ao qual apresenta-se mais apropriado em termos de aplicabilidade científica e não possui restrições legais ou técnicas. Para além da importante revisão conceitual, o artigo discorre sobre a importância desses espaços em termos da gestão e sob a égide dos Objetivos do Desenvolvimento Sustentável propostos pela Organização da Nações Unidas. Por fim, há uma reflexão da importância de estabelecer os espaços verdes urbanos como equipamentos urbanos e terem vitalidade para a efetividade da sustentabilidade nas cidades.

Palavras-chave: Espaços Verdes Urbanos. Áreas Verdes Urbanas. Sustentabilidade. Equipamentos Urbanos.

\section{URBAN GREEN SPACES: REVIEWING PARADIGMS}

Abstract: Although the concept of urban green areas seems crystallized in the Brazilian scientific literature, after the enactment of Law $n^{0}$ 12.651/2012, the term has a different but less widespread application. It was found that the term urban green areas does not apply to most studies and technical-scientific analyzes, since urban green areas would have to be located in places unavailable for housing, as explained in this article. The authors correlate urban green areas with the term urban green spaces, which is more appropriate in terms of scientific applicability and has no legal or technical restrictions. In addition to the important conceptual review, the article discusses the importance of these spaces in terms of management and under the aegis of the Sustainable Development Goals. Finally, there is a consideration on the importance of establishing urban green spaces as urban equipment and having vitality for the sustainability effectiveness in cities.

Keywords: Urban Green Spaces. Urban Green Areas. Sustainability. Urban Facilities.

\footnotetext{
1 Universidade de Brasília, Centro de Desenvolvimento Sustentável, Brasília, Brasil, romerogomes1@gmail.com, https://orcid.org/0000-0002-4553-3498

2 Universidade de Brasília, Departamento de Geografia, Brasília, Brasil, clima86@gmail.com, https://orcid.org/0000-0003-2684-8459

${ }^{3}$ Universidade de Brasília, Centro de Desenvolvimento Sustentável e Departamento de Ecologia, Brasília, Brasil, carlos.h.saito@hotmail.com, https://orcid.org/0000-0002-5757-9629
} 


\section{ESPACIOS VERDES URBANOS: REVISIÓN DE PARADIGMAS}

Resumen: Aunque el concepto de áreas verdes urbanas estar cristalizado en la literatura científica brasileña, después de la promulgación de la Ley nํ1․ 12.651/2012 el concepto comenzó a tener una aplicación diferente, pero poco extendida. Se encontró, por lo tanto, que el término "áreas verdes urbanas" no se aplica a la mayoría de los estudios y análisis técnico-científicos, ya que las áreas verdes urbanas tendrían que ubicarse en lugares no disponibles para la vivienda, como se explica en este artículo. Luego, los autores correlacionan las áreas verdes urbanas con el concepto espacios verdes urbanos, que es más apropiado en términos de aplicabilidad científica y no tiene restricciones legales o técnicas. Además de la importante revisión conceptual, el artículo analizo la importancia de estos espacios en términos de gestión de acuerdo con los Objetivos de Desarrollo Sostenible propuestos por las Naciones Unidas. Finalmente, se reflexiona sobre la importancia de establecer espacios verdes urbanos como equipamiento urbano y tener vitalidad para la efectividad de la sostenibilidad en las ciudades.

Palabras clave: Espacios Verdes Urbanos; Áreas Verdes Urbanas; Sostenibilidad; Equipamiento Urbano

\section{Introdução}

Considerando a importância da revisão conceitual do termo áreas verdes urbanas, Macedo (1995 p. 16) reitera a amplitude do termo ao afirmar que o conceito "designa toda e qualquer área plantada, tendo um significado social expressivo ou não". Da mesma forma Loboda e De Angelis (2005) relatam que as áreas verdes urbanas apresentam uma grande variedade de tipos, estruturas, formas e funções. Podem ser espaços construídos como jardins, parques, praças, cemitérios arborizados ou áreas como florestas urbanas e áreas protegidas para a conservação da natureza e/ou da paisagem (LOBODA; DE ANGELIS, 2005).

Apesar da amplitude conceitual, Macedo (1995) não considera apropriado designar todas praças, parques, hortos e bosques urbanos como áreas verdes urbanas, uma vez que nestes casos nem sempre necessitam de vegetação para desempenhar função social no espaço. Nesses casos, "a utilização do termo sistema de espaços livres públicos de lazer e/ou conservação é precisa e objetiva e evita o uso irresponsável do conceito para os mais diversos fins" (MACEDO, 1995, p. 17).

No mesmo viés, Abreu e Oliveira (2004) relatam que não podem ser considerados áreas verdes urbanas aqueles lugares que integram os espaços livres previstos no inciso I, do art. 4ํㅡㄹ da Lei no 6776 de 1979 - Lei Parcelamento do Solo Urbano (BRASIL, 1979). Tais áreas são denominadas de faixas non edificandi, determinadas pelo inciso III do mesmo artigo, quais sejam: lotes sem construções ou quintais de casas. 
O artigo 22 da referida Lei do Parcelamento do Solo Urbano ainda estabelece que para o registro de loteamento é preciso a constituição e integração ao domínio público das vias de comunicação, praças e dos espaços livres (BRASIL, 1979). Assim, ao tratar de área verde urbana, é importante destacar que ela está dentro das classificações de espaço livre, conforme descreve Macedo (1995, p. 16).

Tem-se como espaços livres todas as ruas, praças, largos, pátios, quintais, parques, jardins, terrenos baldios corredores externos, vilas, vielas e outros por onde as pessoas fluem no seu dia-a-dia em direção ao trabalho, ao lazer ou à moradia ou ainda exercem atividades específicas tanto de trabalho, como lavar roupas (no quintal ou no pátio), consertar carros, etc., como de lazer (na praça, no playground etc.)

A seguir, as demais classificações de espaços livres, descritas por Lima et al. (1994). a) Parque urbano: são áreas verdes, maiores que as praças e jardins, com forte apego às funções ecológicas, no entanto, atividades esportivas, de descanso ou cultural são permitidas. b) Praça: não pode ser considerada uma área verde caso não haja vegetação e seja impermeabilizada. Considera-se quando apresenta vegetação e jardins e sua função principal é de lazer, além da estética. c) Arborização urbana: São os elementos vegetais de porte arbóreo tais como árvores e arbustos no ambiente urbano, geralmente plantados ao longo das ruas, avenidas e calçamentos.

Reitera-se aqui que o artigo $4^{\circ}$ da Lei do Parcelamento do Solo Urbano, ao explicitar critérios imprescindíveis à implantação de um loteamento urbano, mostra que as definições descritas anteriormente são complementares quanto à importância, como os que constam em seu inciso l:

as áreas destinadas a sistemas de circulação (vias públicas que podem ter arborização urbana), a implantação de equipamentos urbanos e comunitários bem como a espaços livres de uso público, serão proporcionais à densidade de ocupação prevista pelo plano diretor ou aprovada por lei municipal para a zona em que se situem (BRASIL, 1979).

Assim, Macedo (1995) afirma que é comum a confusão conceitual entre área verde e de espaço livre. Isso devido às ideias consagradas no imaginário popular de que as áreas verdes precisam ter fins de lazer, assim como os espaços livres. "Este ideário associa na existência simples de áreas vegetadas ou ajardinadas dentro do urbano, a possibilidade de seu uso exclusivo e imediato para o lazer" (MACEDO, 1995, p. 16). 
Diante da amplitude conceitual das áreas verdes urbanas, Silva (2012) salienta que nelas admite-se certos tipos de construção, só que em proporção reduzida. Para o autor, o que caracteriza as áreas verdes urbanas é a existência de vegetação contínua (independente do porte), amplamente livre de edificações, ainda que recortada de caminhos, vielas, brinquedos infantis e equipamentos de atividades esportivas, quando tais áreas se destinem ao uso público.

Na definição de Nucci (2001), há destaque para as funções essenciais dessas áreas: estética (paisagística), ecológica e lazer (social). Diferentes autores investigaram e forneceram evidências dos benefícios gerados pelas áreas verdes urbanas, seja em nível ecológico (MAZZEl et al., 2007), social (AMATO-LOURENÇO et al., 2016) e econômico (COSTA, 2008). A multifuncionalidade das áreas verdes se reflete em benefícios diversos aos usuários de diferentes perfis (crianças, idosos, jovens) e ao meio ambiente urbano.

Dando enfoque à questão social, Lima et al. (1994) enfatizam a importância do uso das áreas verdes urbanas para a recreação da população. No mesmo sentido, Cavalheiro e Del Picchia (1992) incluem as áreas verdes como parte de equipamentos urbanos que, materializadas em parques, jardins, playgrounds ou campings, exercem a função de agregar, sociabilizar e melhorar a qualidade de vida da população. Quando se possibilitam atividades sociais, as áreas verdes são mais utilizadas e apropriadas, sendo associadas à imagem de um bairro ou cidade, ajudando a formação da identidade de uma comunidade (COSTA, 2008).

Ante as definições técnicas, cabe evidenciar agora que a legislação federal brasileira definiu as áreas verdes urbanas na Lei no 12.651/2012, também conhecida por Novo Código Florestal (BRASIL, 2012). De acordo com o art. 3ํ, inciso XX, entende-se por área verde urbana

\begin{abstract}
espaços, públicos ou privados, com predomínio de vegetação, preferencialmente nativa, natural ou recuperada, previstos no Plano Diretor, nas Leis de Zoneamento Urbano e Uso do Solo do Município, indisponíveis para construção de moradias, destinados aos propósitos de recreação, lazer, melhoria da qualidade ambiental urbana, proteção dos recursos hídricos, manutenção ou melhoria paisagística, proteção de bens e manifestações culturais (BRASIL, 2012, grifo do autor).
\end{abstract}

Nesse contexto, o conceito legal atual converge com os conceitos técnicos de áreas verdes urbanas usados por vários autores (HARDT, 1994; LIMA et al., 1994; MACEDO, 1995; NUCCI, 2001), nas seguintes características: áreas com 
predomínio de vegetação, sem levar em conta o seu porte, apresentam alta percentagem de solos não impermeabilizados e cobertos por vegetação.

Com isso, apesar das convergências em algumas características básicas, há que se atentar com rigor para o fato de que desde 2012 nenhuma localidade pode ser considerada área verde urbana se ela possuir moradias. Ademais, a Lei oㅡ 12.651/2012 conceitua que para uma área ser considerada área verde urbana, ela deve estar prevista no Plano Diretor, nas Leis de Zoneamento Urbano e Uso do Solo do Município, caso contrário não se configura como tal. Tem-se, então, o enrijecimento do conceito e, para além disso. há que se amadurecer o debate com relação à aplicação do conceito, principalmente sobre a legislação limitar ou não a criação de áreas verdes em espaços onde, por exemplo, pode haver interesse privado.

Assim sendo, a criação de áreas verdes urbanas fica sujeita ao interesse dos gestores municipais, tanto em áreas públicas quanto para criação de loteamentos privados. A depender do Poder Público Municipal, as áreas verdes podem ser criadas em locais menos valorizados, priorizando-se locais para empreendimentos privados, por exemplo. Considerando a escassez de espaços em grandes centros urbanos, esse é um debate fundamental a ser feito com maior rigor.

O fato é que as áreas verdes urbanas, independentemente da denominação, precisam fazer parte do domínio público do munícipio e em alguns deles as leis de parcelamento do solo determinam que nos projetos de loteamentos sejam destinados percentuais dessas áreas para o cumprimento deste fim. Isso pela importância socioecológica dessas áreas (ABREU; OLIVEIRA, 2004).

\section{Espaços Verdes Urbanos: O Conceito que Emerge}

Dado que a conceituação legal de áreas verdes urbanas (BRASIL, 2012) exclui as áreas disponíveis para a construção de moradias, significa que após a vigência do Novo Código Florestal, este conceito não se aplica na maioria dos estudos científicos que consideram as áreas verdes urbanas como objeto de estudo. Esta incompatibilidade no uso do termo áreas verdes urbanas é verificada por exemplo nos seguintes estudos: Ávila e Pancher (2015); Bargos e Matias (2011); Farias, Bargos e Matias (2016); Silva (2018).

Embora haja inúmeras técnicas e metodologias de sensoriamento remoto aplicadas ao mapeamento das áreas (in)disponíveis para moradia, poder-se-ia pensar na adoção de uma metodologia-padrão para excluir as áreas disponíveis 
para moradia e assim adotar o termo áreas verdes urbanas. No entanto, pelo Estatuto da Cidade (BRASIL, 2001), as informações sobre (in)disponibilidade de áreas para a construção de moradias deveriam considerar o caráter técnicocientífico, mas são estritamente políticas, advindas dos planos diretores discutidas no âmbito do poder legislativo municipal.

Em tese, as prefeituras deveriam indicar tais áreas (in)disponíveis para moradia, seja nos planos diretores municipais ou a menos a caráter do planejamento urbano municipal. No entanto, as administrações municipais quando as possuem, seja por ausência ou carência de recursos técnicos e financeiros, não as disponibilizam em mapas e tampouco de forma digital. Ademais, são dados que podem e precisam ser atualizados ao longo do tempo, mas a ausência deles dificultam assim um levantamento sistemático e atual desse tipo de informação.

Relata-se, ainda, que não há no Brasil um sistema único ou repositório de informações cartografadas referentes à (in)disponibilidade de áreas para moradias. O máximo de informações sobre delimitação territorial das cidades são referentes aos setores censitários (urbanos, periurbanos e rurais) estabelecidos pelo IBGE a fim de levantamento das informações socioeconômicas para o censo demográfico.

Diante desses fatos, o presente artigo advoga pelo uso do conceito de espaços verdes urbanos (EVU) como o mais adequado para se referir aos mapeamentos de áreas verdes nas cidades brasileiras, principalmente quando não se tem certeza sobre a (in)disponibilidade de moradias. Esse conceito está amparado na descrição de espaços verdes de Macedo (1995, p. 16):

Toda área urbana ou porção do território ocupada por qualquer tipo de vegetação e que tenham um valor social [...]. O valor social atribuído pode ser vinculado ao seu utilitarismo em termos de área de produção de alimentos, ao interesse para a conservação ou preservação de conjuntos de ecossistemas ou mesmo de um único ecossistema, ao seu valor estético/cultural e mesmo a sua destinação para o lazer.

Dessa feita, é importante mencionar o estudo de Taylor e Hochuli (2017), que destaca que a denominação espaço verde (green space, tradução literal do inglês) é a mais usual na literatura científica internacional, sobretudo para pesquisas de âmbito inter/multidisciplinar. Os autores realizaram um levantamento em importantes repositórios de artigos científicos (CABI, BioSIS Previews e Medline) que buscou 367 publicações, entre 1975 e 2014, que utilizaram o termo green spaces ou grenspaces (TAYLOR e HOCHULI, 2017). 
Como informa a referida pesquisa, a ampla maioria são artigos do século $\mathrm{XXI}$, isso mostra a emergência e atualidade do uso do termo espaços verdes. Taylor e Hochuli (2017) relatam ainda que o contexto urbano é o mais analisado embora haja outros (áreas naturais, não urbanas), o que mostra a necessidade do adjetivo "urbano" na nomenclatura quando o recorte da análise não for rural.

Quanto à definição dos espaços verdes, Taylor e Hochuli (2017) relatam a amplitude conceitual do termo. Os autores conseguiram estabelecer seis tipos de definições diferentes (Tabela 1). Isso sugere que os pesquisadores não têm a mesma compreensão de espaço verde devido aos seus múltiplos contextos e áreas de análises (TAYLOR; HOCHULI, 2017).

Tabela 1 - Tipos de definição de espaços verdes (TAYLOR; HOCHULI, 2017)

Tipo de definição

\begin{tabular}{cl}
\hline Tipo de definição & \multicolumn{1}{c}{ Descrição } \\
\hline & Definição que \\
& reconhece um intervalo \\
daquilo que se \\
considera espaço \\
verde.
\end{tabular}

Por exemplos

Exemplos que ilustram os espaços verdes.

Exemplos que incorporam serviços ecossistêmicos, como

Serviços ecossistêmicos

Áreas verdes

Uso da terra

Áreas com vegetação a agricultura urbana e/ou uma referência relacionada às necessidades humanas.

Uma referência às áreas verdes e/ou naturais sem maiores detalhamentos.

O uso da terra descreve espaço verde.

Áreas que contenham vegetação.
Exemplo

O espaço verde é descrito pelo nível de vegetação, que vai de ruas paisagísticas, caminhos arborizados para campos de recreação e parques cobertos de floresta (ALMANZA et al., 2012).

Espaços que combinam: áreas abertas, plantadas, urbanas abertas, pastagens, florestas e plantas perenes (TAVERNIA; REED, 2009).

Um tipo de uso da terra que apresenta contribuições aos ambientes urbanos em termos ecológicos, estéticos, de saúde pública e que também atende as necessidades básicas humanas (AYDIN; ÇUKUR, 2012).

A área investigada inclui substanciais elementos verdes (GENTIN, 2011).

Espaço de recreação ou inutilizado (BOONE-HEINONEN et al., 2010).

Espaço verde no sentido de ser predominantemente coberto de vegetação (HECKERT, 2013).

Fonte: Tradução de Taylor; Hochuli (2017, p. 27). 
Dada a amplitude conceitual, Taylor e Hochuli (2017) remetem à importância da definição clara de cada pesquisa que inclua os espaços verdes no seu escopo. Ademais, recomendam que a definição abarque elementos quantitativos e qualitativos de modo a torná-lo mais aplicável.

Por fim, Taylor e Hochuli (2017) ratificam a necessidade de as pesquisas utilizarem o termo espaços verdes, independentemente do contexto e disciplinas. A normatização do termo no âmbito científico, agregada a uma definição clara, permite e facilita a realização de meta-análises, estudos comparativos ou mesmo parametrização de referências.

\section{Gestão dos Espaços Verdes Urbanos no Brasil}

No Brasil, a gestão dos espaços verdes urbanos ficou a cargo dos municípios, uma vez que a Constituição Federal (BRASIL, 1988) determinou que os temas de interesse local são competência exclusiva dos municípios. Antes disso, a própria Lei do Parcelamento do Solo Urbano (Lei no 9785/79) deu competência aos municípios para definir os usos permitidos e os índices urbanísticos de parcelamento e ocupação do solo. Nesse contexto, pode definir quanto será destinado aos espaços verdes para preservação, espaços para lazer e uso público, podendo o critério ser definido pelo plano diretor ou por legislação municipal (BRASIL, 1979). Assim, as gestões municipais ficaram encarregadas de definir e gerir diretamente tais espaços.

O poder legislativo federal vem pautando algumas discussões e projetos de lei que envolvem os espaços verdes urbanos. Atualmente existe um Projeto de Lei (PL) específico na temática em destaque no senado federal pelo PL no 396 (BRASIL, 2014). Esse projeto obriga a delimitação das áreas verdes urbanas pelos planos diretores municipais. O texto proposto modifica o Estatuto da Cidade (BRASIL, 2001) e obriga os municípios a incluírem nos seus planos diretores o planejamento e delimitação de todas as áreas verdes urbanas, além das zonas urbanas passíveis de reflorestamento.

Quanto aos espaços verdes que formam as Áreas de Preservação Permanente (APP), elas estão amparadas de acordo com o Novo Código Florestal Lei Federal no 12.651 (BRASIL, 2012). Porém, há uma discussão se aquelas dentro das áreas urbanas deveriam ser estabelecidas por legislações municipais. Os que advogam a favor citam a insegurança jurídica daquelas cidades que historicamente instalaram-se próximo aos cursos d’água justamente para usufruir do fundamental abastecimento hídrico. 
Nesse sentido, destacam-se aqui dois PLs, um na câmara federal ( $n$ ํ 6830 2013) e outro no senado federal ( $n$ - 368 - 2012), propondo que os municípios passem a legislar sobre as APP urbanas. Apesar da pertinência de se observar características locais para a definição da largura das faixas marginais das APP, Hulsmeyer e Macedo (2015) citam a fragilidade técnica e financeira da maioria dos municípios como motivo de preocupação se esses PLs forem levados para frente.

Aprovar as referidas legislações sem diretrizes que incorporem as diferentes características e padrões morfológicos das APP urbanas pode servir de instrumento para legalizar a redução das faixas marginais das APP, ampliando as áreas sem cobertura vegetal e com edificações (HULSMEYER; MACEDO, 2015). Entretanto, considerando que as APP urbanas estão localizadas em áreas geograficamente frágeis, como alta declividade, geralmente com pouca vegetação nativa e presença de corpos d’água, quaisquer medidas que visem à redução da vegetação poderão aumentar as áreas de riscos e ocasionar desastres ambientais, além dos prejuízos socioeconômicos.

Mesmo que os referidos PLs tenham boa intenção, deve-se ponderar que a obrigatoriedade de execução da lei recai apenas aos municípios. Estabelecer mais uma obrigação ao ente federativo que menos tem recurso técnico e financeiro para executá-la talvez não dê resultados efetivos. Tão importante quanto as obrigações é criar mecanismos de incentivos técnicos e financeiros para efetivar estudos que garantam a permanência dos espaços verdes urbanos.

\section{Espaços Verdes Urbanos e o Paradigma da Sustentabilidade}

Considerando a importância socioambiental dos espaços verdes urbanos em nível global e de como correlacionam-se com outros fatores que interferem na qualidade de vida, destaca-se aqui que a Cúpula das Nações Unidas sobre o Desenvolvimento Sustentável (Nova York - 2015) criou a Agenda 2030. Essa agenda descreve um plano de ação, assinado por 193 países, para o alcançar 17 Objetivos do Desenvolvimento Sustentável (ODS). Estabeleceu-se assim 169 metas para alcançar as ODS até 2030 (ONU, 2015a).

O objetivo $\mathrm{n}^{0}$ 11, que visa à sustentabilidade nas cidades e comunidades, apresentou sete metas. Duas delas se relacionam com a importância de implantação dos espaços verdes como equipamentos urbanos nas cidades ou comunidades. $A$ meta 11.7 se relaciona de forma direta ao estabelecer que "até 2030, proporcionar o acesso universal a espaços públicos seguros, inclusivos, acessíveis e verdes, em 
particular para as mulheres e crianças, pessoas idosas e pessoas com deficiência" (ONU, 2015b, p. 25). Essa meta evidencia que os espaços verdes que funcionam como equipamentos urbanos promovem a inclusão social.

Assim, a meta 11.3, ao propor que se "aumente a urbanização inclusiva e sustentável, e a capacidade para o planejamento e a gestão participativa, integrada e sustentável dos assentamentos humanos" (ONU, 2015b, p. 25), evidencia que os espaços verdes estão diretamente relacionados. Ao se propor espaços verdes como equipamento urbano em comunidades carentes de infraestrutura urbana, além do espaço de convivialidade, inclusão e participação, a sociedade tende a apropriá-la. Com o sentimento de pertencimento por parte da população, os espaços verdes poderão ser mais protegidos estabelecendo sinergia dos benefícios sociais, ambientais e econômicos nas áreas onde forem implantados.

Para tornar os espaços verdes urbanos instrumentos que possam melhorar a qualidade de vida no seu entorno é preciso tratá-los como equipamento urbano. Isso porque os espaços verdes também têm uma função social relacionada à atividade de lazer, recreação, sociabilização e promoção de atividades culturais e educacionais (BARGOS; MATIAS, 2011). A Figura 1 mostra o Parque Olhos D’Água, situado em Brasília, que cumpre a referida função social.

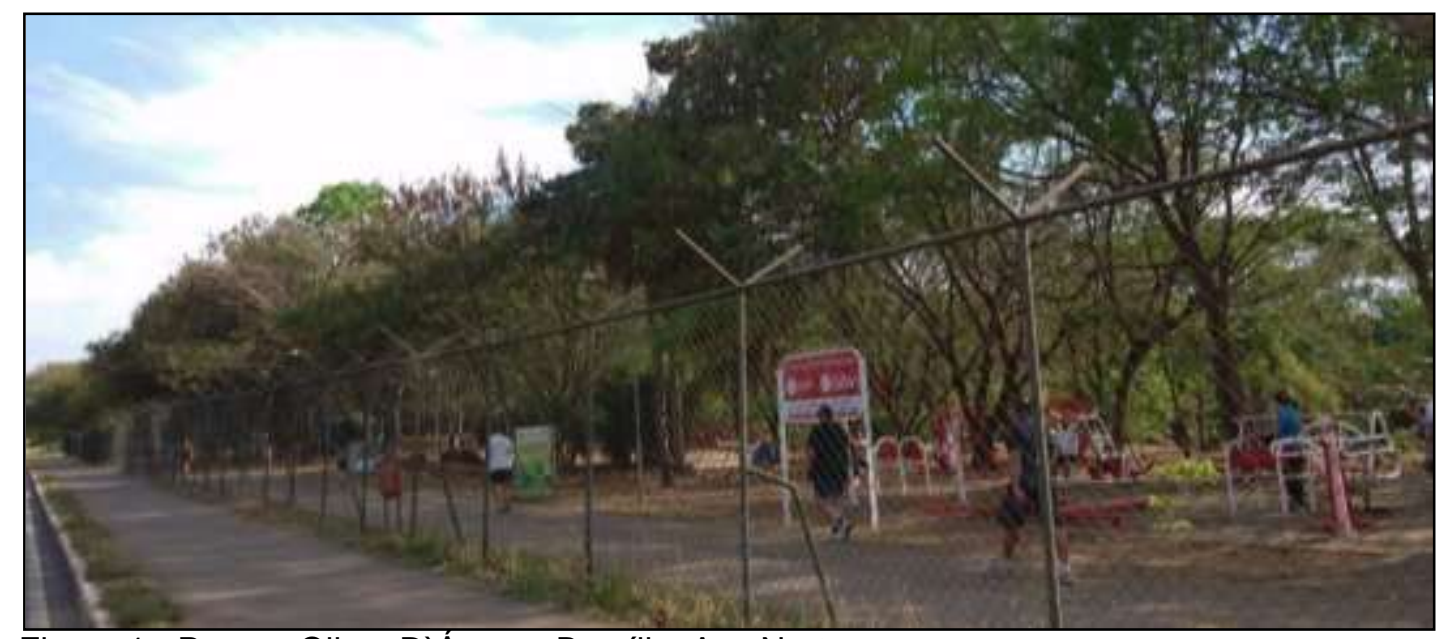

Figura 1 - Parque Olhos D`Água - Brasília, Asa Norte.

Fonte: Autor (2017).

Nesse sentido, cabe destacar o conceito de equipamento urbano conforme a Associação Brasileira de Normas Técnicas - NBR 9284: "designa todos os bens públicos ou privados, de utilidade pública, destinado à prestação de serviços necessários ao funcionamento da cidade" (ABNT, 1986, p. 1).

Porém, para entender o que são serviços necessários à cidade, é preciso analisar a Lei do Parcelamento do Solo (6.766/79). Cabe destaque o art. 5으, 
parágrafo único, o qual restringe os equipamentos urbanos aqueles relacionados à infraestrutura necessária à expansão da cidade, como: "escoamento das águas pluviais, iluminação pública, esgotamento sanitário, abastecimento de água potável, energia elétrica pública e domiciliar e vias de circulação" (BRASIL, 1979).

Ao cumprir funções socioambientais essenciais que vão desde o auxílio à drenagem urbana, tamponamento do microclima, à redução da erosão e poluição do ar, tem-se claro que os espaços verdes urbanos necessitam compor a infraestrutura das cidades. Nesse ponto, ao se analisar conjuntamente os conceitos legal e técnico de equipamentos urbanos, depreende-se que eles deveriam ser considerados bens de utilidade pública necessários para o funcionamento e para o planejamento sustentável das cidades.

Segundo Francis (1989), as áreas verdes urbanas (mas, nesse estudo denominadas EVU) podem ser vistas como "espaços participativos", ou seja, elementos nucleares da vida urbana que reflitam culturas, crenças e valores. A forma mais concreta e efetiva seria pensar esses locais em comunidades carentes de infraestrutura urbana, associadas a outros equipamentos de uso coletivo como centros comunitários de cultura, área esportivas, postos de saúde, escolas ou pontos de práticas de exercícios ao ar livre.

Assim, constata-se a importância dos espaços verdes urbanos e principalmente daqueles que possam ser utilizadas de forma sustentável, garantindo qualidade de vida. Nesse ponto, reitera-se que independente do uso dado aos espaços verdes nas cidades, eles irão cumprir com sua função ecológica (por exemplo: regulação do microclima, retenção de água no solo), mas esse estudo evidencia a potencialidade desses espaços quando possuem condições mínimas de serem utilizadas pela sociedade para lazer, esporte, cultura etc. Assim, ao associar outros equipamentos urbanos de uso coletivo, tais áreas passam a se consolidar como equipamentos urbanos essenciais para a população.

No mesmo sentido, Jacobs (2011) argumenta que não basta estabelecer um espaço verde para a garantia da sua vitalidade e do seu entorno. A valorização de um bairro não é correlacionada apenas com a presença dos espaços verdes. Para tanto, a autora cita que eles precisam ter vitalidade que depende dos seguintes elementos: diversidade de uso da área (área para esportes, descanso, feiras, bancos para descanso), riqueza espacial (lagos, árvores em boa quantidade, jardins), centro bem definido (estrutura de apoio administrativo, com banheiros, 
bebedouros e placas informativas) e delimitação espacial (cercas ou marcos que definam os limites da área) (JACOBS, 2011).

Ao estabelecer a vitalidade conforme a autora supracitada, os espaços verdes têm maior probabilidade de concretizarem-se como equipamentos urbanos para a sociedade. Assim, muitos dos seus benefícios sociais têm sido estudados, analisados e comprovados cientificamente. Amato-Lourenço et al. (2016) fizeram um levantamento de pesquisas que provam a relação positiva entre a disponibilidade dos espaços verdes urbanos para a qualidade de vida.

$O$ referido estudo levantou pesquisas internacionais que afirmam que a proximidade dos espaços verdes com as pessoas vai além dos serviços ecossistêmicos. Por exemplo, associa-se a presença desses espaços com maior longevidade aos praticantes de caminhada nos espaços verdes urbanos (TAKANO; NAKAMURA; WATANABE, 2002), a menores índices de obesidade em crianças que moram perto de parques (DADVAND et al., 2014) e a maior saúde mental para quem visita parques urbanos (VAN DEN BERG et al., 2016).

O fato é que o uso dos espaços verdes diminui o estresse, aumenta a coesão social e a prática de esportes como caminhada, corrida, ciclismo etc. Não à toa, muitas cidades do mundo têm investido em programas pró-espaços verdes de maneira a melhorar a qualidade de vida, como Nova York, com o renomado One Million Trees (MTNYC, 2013). Da mesma forma que a população necessita de saneamento, eletricidade e vias de circulação, é cada vez mais evidente que uma cidade precisa propiciar qualidade de vida. Nesse sentido, os espaços verdes nas cidades se mostram fundamentais à qualidade de vida.

Além da questão de qualidade de vida, ressalta-se a importância econômica de se investir nos espaços verdes urbanos. Estudo publicado pelo Serviço Florestal Americano (NOWAK et al., 2010) mostra que as 3,8 bilhões de árvores situadas em espaços verdes urbanos nos Estados Unidos (EUA) foram avaliadas em 2,4 trilhões de dólares pelos seus benefícios prestados, como: redução da poluição atmosférica, custos associados ao aquecimento e arrefecimento dos prédios, emissões de carbono e retenção da água da chuva (NOWAK et al., 2010).

No estudo mais local, em Portland (estado do Oregon, EUA), os referidos benefícios foram avaliados em 1,53 bilhões de dólares para a cidade (DONOVAN; BUTRY, 2010). Considerando o investimento de apenas 15 milhões de dólares por ano para manter e estabelecer novos EVU, os autores afirmam que esse investimento reduz gastos com infraestrutura urbana e em situações de emergência, 
como alagamentos e desmoronamento. Essa economia de recursos é mais que suficiente para aumentar os espaços verdes e para amortizar o investimento inicial (DONOVAN; BUTRY, 2010).

Apesar da importância dos espaços verdes urbanos, a análise realizada por Rolnik et al. (2015) em duas regiões metropolitanas (São Paulo e Campinas) mostrou que o maior programa habitacional brasileiro (Minha Casa, Minha Vida MCMV) se caracteriza por assentar os moradores de baixa renda em periferias monofuncionais. Ou seja, o programa garante apenas 0 ato de morar num espaço homogêneo: com casas iguais, dispostas em linhas geométricas de forma a otimizar a distribuição das moradias com pouco ou quase nenhum espaço verde.

Assim, os empreendimentos estão localizados em zonas sem oferta de emprego, condições precárias de infraestrutura e insuficiência de equipamentos urbanos (ROLNIK et al., 2015). A Figura 2 mostra um conjunto habitacional do MCMV (Conjunto Brenno Garcia - Gravataí/RS) e nota-se a ausência de árvores dentro do empreendimento, em contraste com a área vizinha.

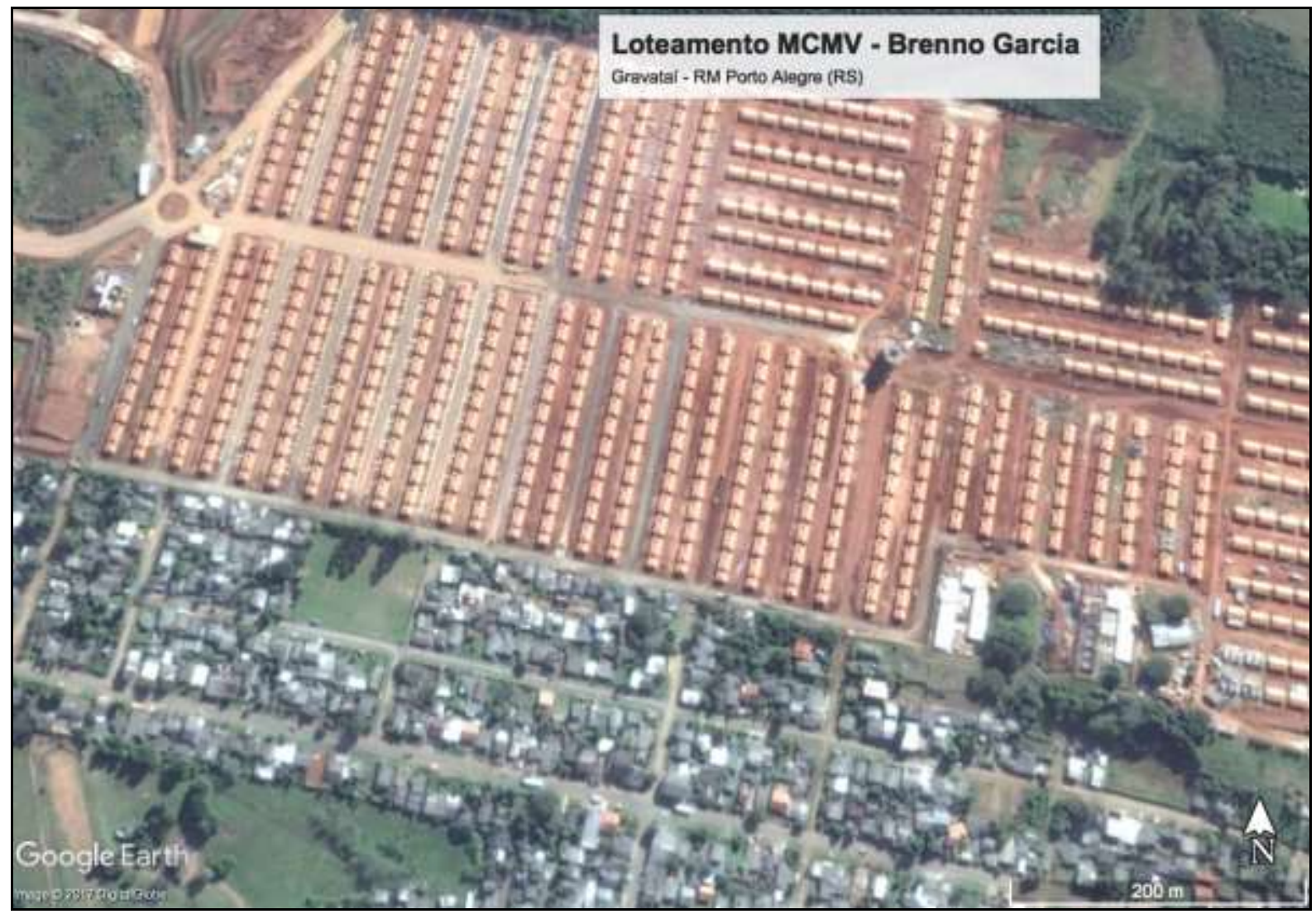

Figura 2 - Conjunto habitacional do Minha Casa Minha Vida: Brenno Garcia - Gravataí (RS) Fonte: Google-Earth (2017)

Contraditoriamente, são nas áreas com maior renda que há maior demanda de projetos e planos para implantação de espaços verdes. Além de aparentemente estarem em áreas mais ricas, há o agravante dos espaços verdes serem cada vez 
mais privados, como por exemplo, condomínios residenciais, edifícios polifuncionais e clubes de lazer, em contraste com praças, parques, vias arborizadas ou outros espaços de uso público e coletivo (LOBODA; DE ANGELIS, 2005).

O desejo de tornar um bairro "sustentável" ou "ecologicamente correto" esconde outras contradições. Por exemplo: espaços verdes amplos e fechados, cercando os condomínios e empreendimentos comerciais e industriais (Figura 3). Esse fato evidencia que os espaços verdes servem, também, para segregar camadas sociais.

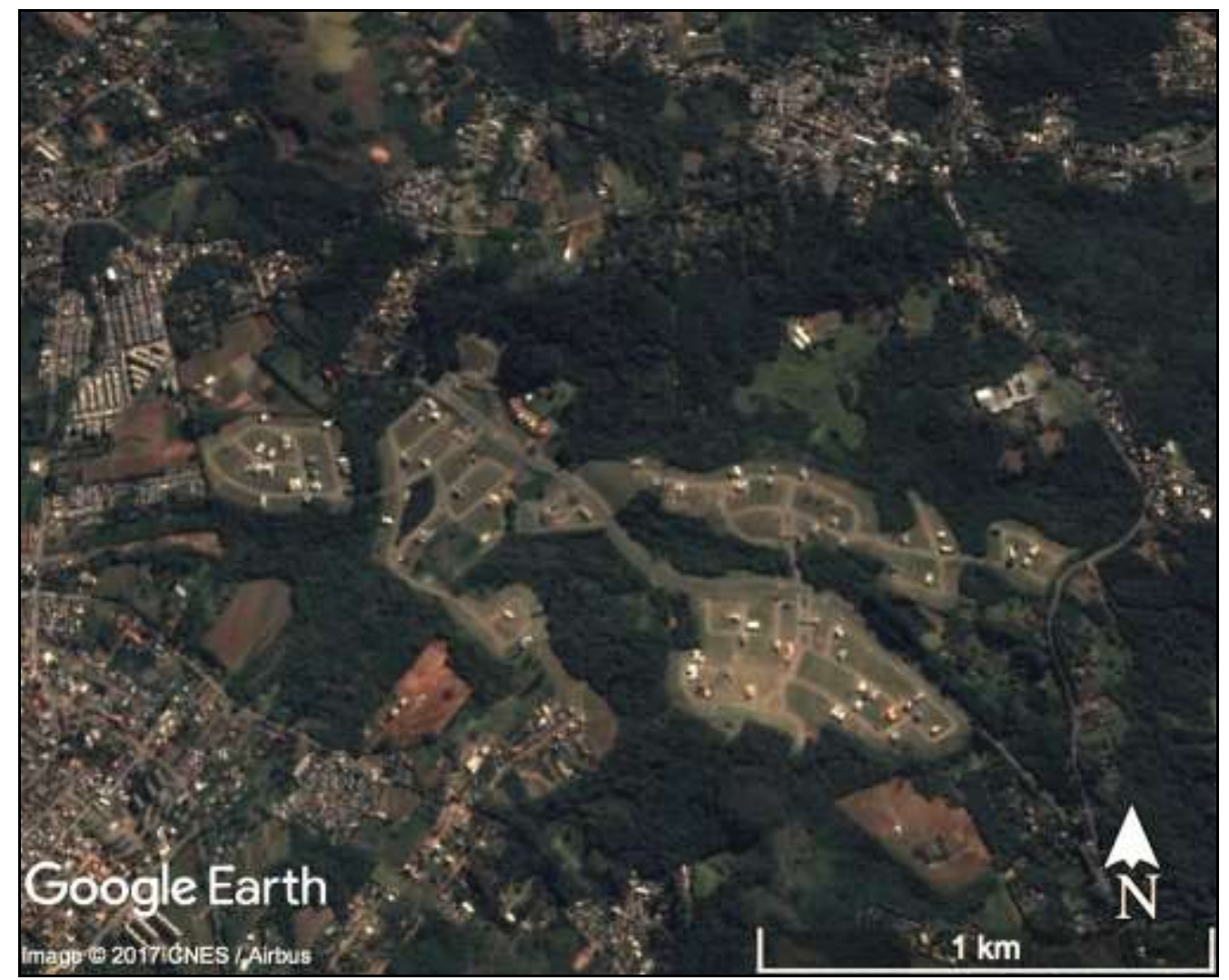

Figura 3 - Condomínio Alphaville cercado de espaços verdes - Porto Alegre. Fonte: Google-Earth (2017)

Estudo de Solecki e Welch (1995) ratifica a afirmação anterior ao analisar parques que separam dois bairros de índices socioeconômicos díspares na cidade de Boston (EUA). "Quando um parque urbano funciona como uma barreira, separando dois bairros, ele trás um empobrecimento aos mesmos, gerando um menor uso do espaço verde, que muitas vezes torna-se uma paisagem abandonada" (SOLECKI; WELCH, 1995, p. 93, tradução nossa). No Brasil, é comum, em várias cidades, dois bairros de rendas distintas serem separados por um parque. Nesse caso, o espaço verde simboliza a manutenção da separação, impossibilitando a aproximação das pessoas (HENRIQUE, 2009). 
Por fim, evidencia-se que tão importante quanto criar e manter os espaços verdes como equipamentos urbanos é promover o que Harvey (1980) denomina de apropriação justa dos espaços públicos. Ou seja, pensar na apropriação desses espaços dentro de um projeto de emancipação coletiva, e não como uma forma de exploração econômica, segregação socioespacial ou marketing ecológico.

Nesse sentido, políticas para minimizar o efeito da segregação socioespacial são usualmente relacionadas com a construção de escolas, hospitais, disponibilidade de serviços públicos e oportunidades de emprego (BUENO; GUIDUGLI, 2004). Porém, apesar do potencial dos espaços verdes urbanos, iniciativas de implantação de parques ou praças nas periferias como meio de enfrentamento das desigualdades sociais (incluindo a segregação socioespacial) possuem lenta expansão nas gestões urbanas.

Vale aqui citar a conclusão final do trabalho de Haase et al. (2017, p. 46, tradução nossa): "Os espaços verdes precisam estar distribuídos uniformemente em uma cidade e providos de vegetação diversa, de modo a garantir que todos os habitantes tenham acesso e benefícios iguais". Para os referidos autores é importante propor a distribuição mais igualitária dos espaços verdes urbanos, sobretudo quando se busca a sustentabilidade nas cidades conjugadas com a inclusão social.

Assim como Carlos (1992, p. 26) caracteriza a cidade como um "modo de viver, pensar, mas também de sentir", os espaços verdes, estando dentro das cidades, também requerem ter vitalidade, ou seja, serem dinâmicos, atraentes, com segurança e infraestrutura adequada. Assim, os espaços verdes como equipamentos urbanos podem ser apropriados, fazendo parte das cidades e integrados à sociedade.

\section{Considerações Finais}

Dada a emergência de estudos relacionados com a importância da cobertura vegetal nas cidades, sobretudo vinculados ao planejamento e sustentabilidade urbana, este artigo alertou sobre a inaplicabilidade do conceito de áreas verdes urbanas (expresso na Lei no 12.651/2012) em diversos estudos e análises técnicocientíficas. Tendo em vista essa inaplicabilidade, uma vez que as áreas verdes urbanas deveriam estar em locais indisponíveis para moradias, foi apresentado como alternativa o uso do termo espaços verdes urbanos (EVU). Conceito esse que 
já foi descrito e discutido na literatura nacional e, sobretudo, está vinculado à maioria dos artigos e pesquisas internacionais.

Mesmo com a sugestão no uso do termo "espaços verdes urbanos", é importante investigar as possíveis consequências do enrijecimento do conceito de "áreas verdes urbanas" proposto na Lei ํㅜ 12.651/2012. Dessa forma, é necessário analisar se houve ou haverá algum tipo de limitação relacionado às políticas públicas para a criação dos espaços verdes urbanos.

Para além da questão conceitual, é importante destacar que a gestão dos EVU recai aos municípios. Ademais, vários projetos de leis federais foram propostos e imputam mais obrigatoriedades aos municípios acerca de tais espaços. Diante disso, é evidenciada a importância da criação de mecanismos de incentivos técnicos e financeiros para efetivar estudos que garantam a permanência e uso dos EVU e não somente obrigações na sua gestão.

Por fim, evidencia-se a relação dos EVU com a sustentabilidade, os quais estão vinculados aos Objetivos do Desenvolvimento Sustentável (ONU, 2015). Para a sua efetividade em termos da sustentabilidade urbana, observa-se a necessidade de estabelecê-los como equipamentos urbanos, terem vitalidade e serem bem distribuídos no espaço, promovendo assim uma maior inclusão social.

\section{REFERÊNCIAS}

ABREU, A. H.; OLIVEIRA, R. Áreas verdes e municípios. Santa Catarina, p. 2, 2004.

ALMANZA, E.; JERRETT, M.; DUNTON, G.; SETO, E.; PENTZ, M. A. A study of community design, greenness, and physical activity in children using satellite, GPS and accelerometer data. Active Living Research, v. 18, n. 1, p. 46-54, 1 jan. 2012.

AMATO-LOURENÇO, L. F.; MOREIRA, T. C. L.; ARANTES, B. L.; SILVA-FILHO, D. F.; MAUAD, T. Metrópoles, cobertura vegetal, áreas verdes e saúde. Estudos Avançados, v. 30, p. 113-130, 2016.

ÁVILA, M. R.; PANCHER, A. M. Estudo das áreas verdes urbanas como indicador de qualidade ambiental no município de Americana-SP. Revista Brasileira de Cartografia, v. 67, n. 3, p. 527-544, 2015.

AYDIN, M. B. S.; ÇUKUR, D. Maintaining the carbon-oxygen balance in residential areas: A method proposal for land use planning. Urban forestry \& urban greening, v. 11 , n. 1 , p. 87-94, 2012. 
BARGOS, D. C.; MATIAS, L. F. Áreas verdes urbanas: um estudo de revisão e proposta conceitual. Revista da Sociedade Brasileira de Arborização Urbana, v. 6, n. 3, p. 172-188, 2011.

BOONE-HEINONEN, J.; CASANOVA, K.; RICHARDSON, A. S.; GORDONLARSEN, P. Where can they play? Outdoor spaces and physical activity among adolescents in U.S. urbanized areas. Preventive Medicine, v. 51, n. 3, p. 295-298, 1 set. 2010.

BRASIL. Lei Federal n 6766. Dispõe sobre o Parcelamento do Solo Urbano e dá outras providências. 20 dez. 1979.

BRASIL. Constituição da República Federativa do Brasil. Constituição Federal. 1988.

BRASIL. Lei Federal n 10.257. Estatuto da Cidade (Atos do Poder Legislativo). 2001.

BRASIL. Lei federal n 12.651. Novo Código Florestal. 25 maio 2012, p. 2.166-67.

BRASIL. PL n 396. PL Senado Federal: Estabelece diretrizes gerais da política urbana e dá outras providências (Estatuto da Cidade), para dispor acerca da delimitação das áreas verdes urbanas. 2014.

BUENO, E. P.; GUIDUGLI, O. S. A geografia e o estudo da segregação socioespacial. Geografia, Rio Claro, v.29, n.1, p.71-85. 2004.

CARLOS, A. F. A. A cidade. São Paulo: Livraria da Fisica, 1992.

CAVALHEIRO, F.; DEL PICCHIA, P.C.D. Áreas verdes: conceitos, objetivos e diretrizes para o planejamento. In: CONGRESSO BRASILEIRO SOBRE ARBORIZAÇÃO URBANA E IV ENCONTRO NACIONAL SOBRE ARBORIZAÇÃO URBANA. 1. Anais... Vitória, ES, p. 29-38. 1992.

COSTA, C. O verde como propulsor do desenvolvimento urbano: exemplos das exposições de paisagismo na Alemanha. Malha Urbana: Revista Lusófona de Urbanismo, v. 6, n. 6, p. 1-21, 2008.

DADVAND, P.; VILLANUEVA, C. V.; FONT-RIBERA, L.; MARTINEZ, D.; BASAGANA, X.; BELMONTE, J,; VRIJHEID, M.; GRAZULEVICIENE, R.; KOVEGINAS, M.; NIEUWENHUIJSEN, M. J. Risks and benefits of green spaces for children: a cross-sectional study of associations with sedentary behavior, obesity, asthma, and allergy. Environmental Health Perspectives (Online), v. 122, n. 12, p. 1329, 2014.

DONOVAN, G. H.; BUTRY, D. T. Trees in the city: Valuing street trees in Portland, Oregon. Landscape and Urban Planning, v. 94, n. 2, p. 77-83, 2010.

FARIAS, F. O.; BARGOS, D. C.; MATIAS, L. F. Aplicação de geotecnologias no estudo da relação entre a valorização da terra urbana e a presença de áreas verdes 
na cidade de Paulínia (SP). Revista Brasileira de Cartografia, Aplicação dos SIGs. v. 68, n. 2, p. 275-287, 2016.

GENTIN, S. Outdoor recreation and ethnicity in Europe - A review. Urban Forestry \& Urban Greening, v. 10, n. 3, p. 153-161, 1 jan. 2011.

HAASE, D.; KABISCH, S.; HAASE, A.; ANDERSSON, E., BANZHAF, E., BARÓ, F.; KRELLENBERG, K. Greening cities-To be socially inclusive? About the alleged paradox of society and ecology in cities. Habitat International, 64, p. 41-48, 2017.

HARDT, L. P. A. Subsídios ao planejamento de sistemas de áreas verdes baseado em princípios de ecologia urbana: aplicação a Curitiba-PR.

Dissertação apresentada ao Curso de Pós-Graduação em Engenharia Florestal - Curitiba - PR: Universidade Federal do Paraná, 1994.

HARVEY, D. A Justiça Social e a Cidade. Tradução: Armando Corrêa Da Silva. São Paulo: Hucitec, 1980.

HECKERT, M. Access and equity in greenspace provision: A comparison of methods to assess the impacts of greening vacant land. Transactions in GIS, v. 17, n. 6, p. 808-827, 2013.

HENRIQUE, W. O direito à natureza na cidade. 1. ed. Salvador: Edufba, 2009. HULSMEYER, A. F.; MACEDO, S. S. APPs urbanas e as mudanças no código florestal: diretrizes para a legislação municipal. Faculdade de Arquitetura e Urbanismo - USP, 2015. Disponível em: <http://quapa.fau.usp.br/wordpress/wpcontent/uploads/2015/11/APPS-urbanas-e-as-mudanças-no-código-florestaldiretrizes-para-a-legislação-municipal.pdf>. Acesso em: 7 set. 2017

JACOBS, J. Morte e vida de grandes cidades. 3. ed. Brasil: Martins Fontes, 2011. LIMA, A. M. L. P.; CAVALHEIRO, F., NUCCI, J. C., SOUZA, M. A. L. B.; FIALHO, N. D. O.; DEL PICCHIA, P. C. D. Problemas de utilização na conceituação de termos como espaços livres, áreas verdes e correlatos. Congresso Brasileiro de Arborização Urbana. In: Congresso Brasileiro sobre Arborização Urbana. p. 539-550. 1994.

LOBODA, C. R.; DE ANGELIS, B. L. D. Áreas verdes públicas urbanas: conceitos, usos e funções. Ambiência, v. 1, n. 1, p. 125-139, 2005.

MACEDO, S. S. Espaços livres. Paisagem e ambiente, n. 7, p. 15-56, 1995. MAZZEI, K.; MUNO COLESANTI, M. T.; GOMES DOS SANTOS, Douglas. Áreas verdes urbanas, espaços livres para o lazer. Sociedade \& Natureza, v. 19, n. 1, 2007.

MTNYC. One Million trees, 2013. Disponível em: <http://www.milliontreesnyc.org>. Acesso em: 4 abr. 2018.

NOWAK, D. J.; RANDLER, P. B.; GREENFIELD, E. J.; COMAS, S. J.; CARR, M. A.; ALIG, R. J. Sustaining America's urban trees and forests. Mewtown Square, Pensilvânia: United States Department of Agriculture, Forest Service, Northern Research Station, v. 62. 2010. 
NUCCI, J. C. Qualidade ambiental e adensamento urbano: um estudo de ecologia e planejamento da paisagem aplicado ao distrito de Santa Cecília, MSP. São Paulo.

Humanitas, FFLCH/USP, 2001.

ONU. Organização das Nações Unidas. Cúpula das Nações Unidas sobre o Desenvolvimento Sustentável, 2015a. Disponível em:

<https://nacoesunidas.org/pos2015/cupula/>. Acesso em: 6 jul. 2017

ONU. Organização das Nações Unidas. Transformando Nosso Mundo: A Agenda 2030 para o Desenvolvimento Sustentável. Nova York. 2015b.

ROLNIK, R.; PEREIRA, A. L. S.; MOREIRA, F. A.; ROYER, L. O.; IACOVINI, R. F. G.; NISIDA, V. C. O Programa Minha Casa Minha Vida nas regiões metropolitanas de São Paulo e Campinas: aspectos socioespaciais e segregação. Cadernos Metrópole., v. 17, n. 33, p. 127-154, 2015.

SILVA, J. A. Direito urbanístico brasileiro. 7. ed. São Paulo: Malheiros, 2012.

SILVA, L. C. O mapeamento das áreas verdes urbanas de Uberlândia (MG): análise da concentração de investimentos públicos. Dissertação (Mestrado em Geografia) —Catalão - Goiás: Universidade Federal de Goiás, 2018.

SOLECKI, W. D.; WELCH, J. M. Urban parks: green spaces or green walls? Landscape and Urban Planning, v. 32, n. 2, p. 93-106, 1 jun. 1995.

TAKANO, T.; NAKAMURA, K.; WATANABE, M. Urban residential environments and senior citizens' longevity in megacity areas: the importance of walkable green spaces. Journal of epidemiology and community health, v. 56 , n. 12, p. 913-918, 2002.

TAVERNIA, B. G.; REED, J. M. Spatial extent and habitat context influence the nature and strength of relationships between urbanization measures. Landscape and Urban Planning, v. 92, n. 1, p. 47-52, 15 ago. 2009.

TAYLOR, L.; HOCHULI, D. F. Defining greenspace: Multiple uses across multiple disciplines. Landscape and Urban Planning, v. 158, p. 25-38, 2017.

VAN DEN BERG, M.; VAN POPPEL, M.; VAN KAMP, I.; ANDRUSAITYTE, S.; BALSEVICIENE, B.; CIRACH, M.; DANILEVICIUTE, A.; ELIS, N.; HURST, G.; MASTERSON, D.; SMITH, G.; TRIGUERO-MAS, M.; UZDANAVICIUTE, I.; DE WIT, P.; VAN MECHELEN, W.; GIDLOW, C.; GRAZULEVICIENE, R.;

NIEUWENHUIJSEN, M. J.; KRUIZE, H.; MAAS, J. Visiting green space is associated with mental health and vitality: A cross-sectional study in four European cities. Health \& Place, v. 38, p. 8-15, 2016. 


\section{NOTAS DE AUTOR}

\section{CONTRIBUIÇÃO DE AUTORIA}

Romero Gomes Pereira da Silva - Concepção e elaboração do manuscrito. Coleta de dados, Análise de dados, Elaboração do manuscrito, revisão e aprovação da versão final do trabalho.

Cláudia Lins Lima - Participação ativa da discussão dos resultados; Revisão e aprovação da versão final do trabalho.

Carlos Hiroo Saito - Concepção e elaboração do manuscrito. Participação ativa da discussão dos resultados; Revisão e aprovação da versão final do trabalho.

\section{FINANCIAMENTO}

Projeto INCT / Odisseia - Observatório das Dinâmicas Socioambientais: Sustentabilidade e Adaptação às Mudanças Climáticas, Ambientais e Demográficas. Projeto inserido na categoria dos Institutos Nacionais de Ciência e Tecnologia (Chamada INCT - MCTI / CNPq / CAPES / FAPs n.16 / 2014) com recursos financeiros do CNPq, CAPES e FAP-DF.

\section{CONSENTIMENTO DE USO DE IMAGEM}

Não se aplica.

\section{APROVAÇÃO DE COMITÊ DE ÉTICA EM PESQUISA}

Não se aplica.

\section{LICENCCA DE USO}

Este artigo está licenciado sob a Licença Creative Commons CC-BY. Com essa licença você pode compartilhar, adaptar, criar para qualquer fim, desde que atribua a autoria da obra.

\section{HISTÓRICO}

Recebido em: 16-04-2019

Aprovado em: 10-10-2019 